\title{
RECURRENT SELECTION IN SORGHUM POPULATIONS
}

\author{
H. DOGGETT \\ E.A.A.F.R.O./U.S.A.I.D. Cereals Breeding Unit, Serere Research Station, \\ Soroti, Uganda, and the Plant Breeding Institute, Cambridge
}

Received 15.iii.71

\section{INTRODUCTION}

TRADITIONAL methods of breeding improved varieties of mainly selfpollinating crops have been very successful. Success has been greatest when characters controlled by relatively few genetic factors have been the main objects of selection. Height and length of maturity differences, some pest and disease resistances, and some leaf and panicle characters tend to belong to this category. Even in an out-pollinating crop such as maize, initial yield increase may be due largely to major characters, as in Harrison's Kenya hybrid H-611 (Eberhart et al., 1967), where a short cob with many rows crossed to a long cob with few rows gave the plant breeder's dream of a long cob with many rows. Such major characters are seldom under simple major gene control.

Once major characters contributing to yield have been combined, and major defects decreasing yield dealt with, progress in accumulating small positive factors enhancing yield has been slow and uncertain. Yields of sorghum (Doggett, 1970) and cotton (Hearn, 1969) are well below theoretical maximum values. Quinby and Schertz (1970) stated categorically that plant breeders had not increased yielding ability in sorghum until a method of producing hybrid sorghum was devised. Such an opinion expressed after half a century of sorghum breeding supported by thorough and extensive yield testing in the U.S.A. cannot be lightly disregarded.

Characters such as quality and yield controlled by numerous genetic factors require impracticably large population sizes, if the association of all plus factors into a single genome is to be obtained from crosses between parents differing at numerous loci. This can lead to the plant breeder working in a very restricted range of elite material, relative to the total variability available in the crop (Dixon, 1960; Bell, 1968; Whitehouse, 1969). Another weakness of traditional methods of breeding mainly selfpollinating crops lies in the very limited amount of crossing usually practised, resulting in little breaking and recombination in close linkage groups.

The discovery of genetic male-steriles has made possible the development of random-mating populations in some mainly self-pollinating crops. Recurrent selection applied to such populations should be an effective breeding method complementing traditional systems. The chances of recombinations of numerous characters increase as random-mating populations are grown under selection cycle after cycle, so that enormous segregating generations from crosses become unnecessary. Opportunities for linkage rearrangements occur continually, and large numbers of parents can be used in creating the populations, thus sampling more of the available crop variability. Eberhart et al. (1967) described a comprehensive breeding system for maize, and suggested that it might be applied to other crops, using malesterility. Doggett and Eberhart (1968) and Doggett (1968) set out systems 
for applying such breeding methods to sorghum. Doggett (1970) gave a fuller account of the development of the use of male-sterility for population breeding in sorghum. To this should be added that $\mathrm{O}$. J. Webster (personal communication) and other American workers had started to use cytoplasmic sterility to form sorghum populations in 1960 , with $m_{3}$ genetic sterility being added in 1963 (Nordquist, 1965).

In this paper, results from the first attempts at Serere to grope towards effective population breeding methods in sorghum are presented and discussed.

\section{Materials}

The dwarf Coes male-sterile $\left(m s_{3}\right)$ variety was kindly supplied by Dr O. J. Webster from the University of Nebraska. It showed great susceptibility to leaf diseases at Serere. A group of elite Serere varieties was crossed to the $m s_{3}$ stock, and gave rise to the four "PRS" populations. A second group of proven varieties was crossed to the $m s_{3}$ segregates in the $\mathrm{F}_{2}$ generations of the first crosses, and these gave rise to the four "RS " populations. These latter therefore contained $\frac{1}{4}$ Coes germplasm, $\frac{1}{4}$ of the first group of adapted varieties, and $\frac{1}{2}$ of the germplasm from the " back-cross " group of adapted varieties. The proven Serere varieties were classified as restorers or nonrestorers by testing on the cytoplasmic sterile $\mathrm{CK} 60 \mathrm{~A}$, and were further divided into coarse and quality grain types, these divisions resulting in four populations in each group, as shown in table 1.

TABLE 1

Numbers of different proven Serere varieties used to compose the populations

$\begin{array}{lccccc}\text { Coarse } & \begin{array}{c}\text { Quality } \\ \text { grain }\end{array} & \overbrace{3}^{\begin{array}{c}\text { Coarse } \\ \text { grain }\end{array}} & \begin{array}{c}\text { Quality } \\ \text { grain }\end{array} & \text { Total } \\ \text { PRS } & 16 & 16 & 14 & 23 & 69 \\ \text { RS } & 39 & 37 & 23 & 59 & 158\end{array}$

A total of 158 separate varieties was thus used in the populations, in combination with the Coes $m s_{3}$ stock.

\section{(a) Compositing}

In developing the random-mating populations, 90-95 per cent. of the male-steriles were harvested in each generation, the poorest 5-10 per cent. being rejected. All harvesting was done on a grid system, with some 200 plants in each plot of the grid. The best 3-5 per cent. of the fertile plants from the lst segregating generation were harvested and grown as separate bulks, the very best steriles appearing in these subpopulations in the second segregating generation being fed back into the main populations in the third generation. This is termed " recycling", and was done to reduce the effect of any possible association between $m s_{3}$ and poor yield in the Coes stock (see diagram). 


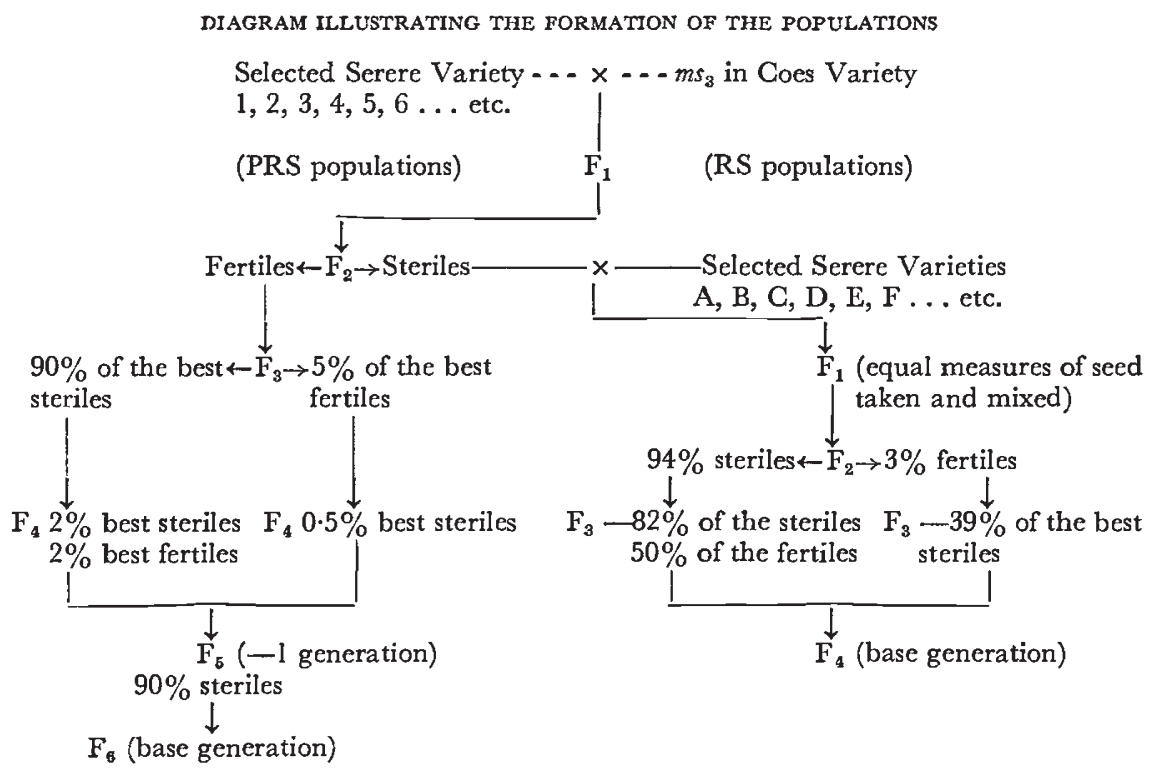

\section{(b) The PRS bulks}

The steriles segregating in the $\mathrm{F}_{2}$ of the cross $\left(m s_{3} \times\right.$ Serere elite varieties) had been used for back-crossing, so the $F_{3}$ bulks for the PRS populations were made by mixing about 40 fertile heads from each $F_{2}$ row. In the $F_{3}$, very tall plants were cut out before flowering, and 90 per cent. of the best steriles were kept for seed, between 180 and 300 plants being taken from each population. Five per cent. of the best fertiles were selected for recycling. In the $\mathrm{F}_{4}, 2$ per cent. of the best steriles and 2 per cent. of the best fertiles were selected as the basis of each population, and to these were added the recycled steriles. Seed for the $F_{5}$ populations was thus taken from between 530 and 600 plants each, of which some 45 per cent. were fertiles, 45 per cent. steriles from $F_{4}$, and 10 per cent. recycled steriles. This $F_{5}$ generation is designated " -1 " in the graphs and tables for the PRS populations. The "base" populations were $\mathrm{F}_{6}$ generation, and were composed entirely from selected male-steriles, the number kept representing some 6-7 per cent. of the total $F_{5}$ populations, each of which had consisted of over 4000 plants. Thus, in terms of effective population size, the $F_{6}$ was based on a selection intensity of some 25 per cent. of the $F_{5}$ populations. It will be noted that some definite selection for yield had been made during the development of these PRS base populations.

\section{(c) The RS populations}

Six to 10 plants were harvested from each $F_{1}$ row of the back-cross, an equal measure of seed was taken from each of these individual row bulks, and thoroughly mixed to form the $\mathrm{F}_{2}$ generation seed. Ninety-four per cent. of the steriles segregating in the $F_{2}$ were kept, which varied from 230 to 370 heads in each of the four populations, while the best 3 per cent. of the fertiles were recycled. Seed for the $\mathrm{F}_{4}$ generation was intended to consist only of steriles from the $\mathrm{F}_{3}$, but some fertile $\mathrm{F}_{3}$ selections taken for progeny row work were included by mistake. Eighty-two per cent. of the $F_{3}$ steriles 
from the main bulk were taken (700 to 1500 per population) and 39 per cent. of the recycled steriles (about 200 per population). To these were added inadvertently 500-600 fertile heads for each population. Seed of each $\mathrm{F}_{4}$ population was thus taken from between 1400 and $2000 \mathrm{~F}_{3}$ plants, and these were the "base" populations for the RS group. The " -1 " populations consisted of the main $\mathrm{F}_{3}$ bulks, and did not include the recycled material.

\section{(d) The evaluation trial}

Remnant seed of each generation, kept in cold storage, was used for the trial. The design chosen was a $9^{2}$ balanced lattice, with a planted plot size of $11 \mathrm{~m} . \times 2 \mathrm{~m}$. (four rows), and a harvest size of $10 \mathrm{~m} . \times 1 \mathrm{~m}$. (two rows). Plant populations were 100,000 plants per hectare, stands were uniformly good, there were no missing plots, and the C. of V. was $9 \cdot 7$ per cent. Observations other than yield measurements were taken in replications 1-3 only on about 50 plants in the discard rows of each plot to avoid trampling on the harvest plots. Observations were therefore not made on the plants actually harvested, and are on a plant number and not an area basis.

\section{Methods}

Populations were grown in isolation from one another, with substantial border discards. During the compositing generations, stands of medium density were used, about 60,000 plants/ha. When the selection systems were begun, stands were increased to 200,000 plants/ha. The populations were divided on a grid system into 25 rectangular plots, each of which contained from 170 to 200 plants. Some 40 of the plants in each plot were malesteriles, which were tagged at flowering. In yield selection, at least double the number of plants finally required was chosen in the field, dried, and the final choice made by weighing in the laboratory.

\section{(a) Female choice mass selection}

The best 10 male-sterile plants were taken from each grid square, so that 250 male-sterile plants provided seed for the following generation.

\section{(b) Alternating female choice and selfed plant mass selection}

Alternate generations were handled exactly as for $(a)$ above. For the remaining generations, the best normal (male-fertile) plants were selected, and these would have been naturally self-pollinated to the extent of at least 90 per cent. Ten plants were taken from each grid square of the base population, but in generations +1 and $+2,20$ plants were taken, giving a carry forward of 500 plants contributing seed to the following generation. There were two alternating series; Series A consisted of the four populations not used for $S_{1}$ testing, and was started with selfed plant selection in the base populations. Series B involved all eight populations, and was started with selfed plant selection in the +1 generation.

\section{(c) $S_{1}$ testing}

Only four populations could be handled as yield testing facilities were limited. Thirteen or 14 fertile plants were chosen by mass selection in each grid of the base populations, and planted in $13^{2}$ triple lattice $S_{1}$ trials, two trials from each population with two control entries in each trial. All entries 
were sibbed in one replication of each trial. Ninety entries from each population were retained, equivalent to about 2 per cent. of the fertile plants in the original base population. Three heads were taken from each trial entry for seed of the recombination generation, but sufficient sibbed steriles were not available, and almost half of the final head number came from selfed plants. Very little selection pressure was applied to the steriles in the recombination $(+2)$ generation, and in two of the populations (PRS 1 and RS 2) the desired number of 250 sterile plants could not be obtained, the +3 generation of these populations being formed from 166 and 144 plants respectively.

Selection intensities are shown in table 2, and in all cases percentages are based on plants of the same kind present, i.e. fertiles as percentage of total fertiles, and steriles as percentage of total steriles.

TABLE 2

Selection intensities used (percentages) based on 20 per cent. samples

\begin{tabular}{ccccccccccc}
\multirow{2}{*}{$\begin{array}{c}\text { Selection } \\
\text { system }\end{array}$} & Generation & PRS 1 & PRS 2 & PRS 3 & PRS 4 & RS 1 & RS 2 & RS 3 & RS 4 \\
Female choice & +1 & 38 & 32 & 44 & 40 & 27 & 29 & 25 & 25 \\
& +2 & 35 & 26 & 45 & 29 & 54 & 30 & 30 & 40 \\
& +3 & 70 & 60 & 56 & 34 & 54 & 54 & 39 & 31 \\
\multirow{5}{*}{ Alternating A } & +1 & - & 6 & 6 & - & 8 & - & - & 6 \\
& +2 & - & 61 & 68 & - & 83 & - & - & 100 \\
\multirow{5}{*}{ Alternating B } & +3 & - & 27 & 30 & - & 28 & - & - & 26 \\
\multirow{5}{*}{ S testing } & +2 & 33 & 28 & 28 & 26 & 22 & 27 & 26 & 27 \\
& +3 & 46 & 48 & 45 & 34 & 57 & 31 & 39 & 20 \\
& $+2 *$ & $2 \cdot 2$ & - & - & $2 \cdot 2$ & - & $2 \cdot 2$ & $2 \cdot 2$ & - \\
& +3 & 100 & - & - & 62 & - & 100 & 79 & -
\end{tabular}

* Based on the number of plants in the base population from which selections were taken for $\mathrm{S}_{1}$ testing.

\section{(d) Selection problems}

(i) Steriles. The proportion of steriles was sometimes very much below expectation, and the contrast between the number of steriles in the populations during the selection period, and the number in the evaluation trial, is evident in table 3.

\section{TABLE 3}

Percentage of steriles found during the selection period $(\boldsymbol{A})$ and in the evaluation trial $(\boldsymbol{B})$. Mean values from all populations used

Selection method

Female choice

Alternating A

Alternating B

$\mathrm{S}_{1}$ testing

\begin{tabular}{|c|c|c|c|c|c|c|c|}
\hline \multicolumn{8}{|c|}{ Generation } \\
\hline & & & & & & & \\
\hline $\mathrm{A}$ & $\vec{B}$ & $\mathbf{A}$ & $\overrightarrow{\mathrm{B}}$ & A & $\vec{B}$ & A & B \\
\hline 17 & 34 & 27 & 42 & 23 & 44 & - & 44 \\
\hline 16 & 33 & 13 & 20 & 13 & 30 & - & 23 \\
\hline 17 & 34 & 27 & 42 & 21 & 30 & - & 32 \\
\hline 17 & 35 & - & - & 13 & 23 & - & 29 \\
\hline
\end{tabular}


The low frequency of steriles in certain generations and populations during the selection phase accounts for the occasions in table 2 when it was necessary to keep all, or nearly all, of the sterile plants, in order to obtain 250 plants for seed of the following generation. The deficiency in steriles during the selection period could be due in part to the failure of observers to identify all the steriles. However, competition was undoubtedly the main

Table 4

Changes in yield under differing systems of selection, dried heads in $\mathrm{kg} . / \mathrm{ha}$

Generation of selection

(1) Female choice

$\begin{array}{lrrrrr}\text { Population } & -1 & \text { Base } & +1 & +2 & +3 \\ \text { PRS 1 } & 5265 & 5495 & 6235 & 6610 & 6480 \\ \text { PRS 2 } & 4065 & 5640 & 5570 & 5940 & 5955 \\ \text { PRS 3 } & 5225 & 6290 & 6200 & 6120 & 6295 \\ \text { PRS 4 } & 5805 & 6160 & 6185 & 6410 & 6275 \\ \text { RS 1 } & 5990 & 6300 & 6495 & 6580 & 6465 \\ \text { RS 2 } & 5735 & 6105 & 5995 & 5975 & 6120 \\ \text { RS 3 } & 4400 & 4600 & 5720 & 5970 & 6055 \\ \text { RS 4 } & 4565 & 5340 & 5835 & 5940 & 5675 \\ \text { Mean } & 5130 & 5740 & 6030 & 6195 & 6165 \\ \text { Mean selection intensity } & 34 & 36 & 50\end{array}$

(2) Alternating $\mathbf{B}$

$\begin{array}{rr}+2 & +3 \\ 5785 & 6715 \\ 4530 & 5735 \\ 5515 & 6385 \\ 6125 & 6290 \\ 6135 & 6585 \\ 5340 & 6390 \\ 5080 & 6600 \\ 5235 & 6395 \\ 5470 & 6385 \\ 27 & 40\end{array}$

(3) Alternating A

$\begin{array}{lrrrrr}\text { Popula- } & & & & & \\ \text { ation } & -1 & \text { Base } & +1 & +2 & +3 \\ \text { PRS 2 } & 4065 & 5640 & 5610 & 6310 & 5720 \\ \text { PRS 3 } & 5225 & 6290 & 5960 & 6560 & 6320 \\ \text { RS 1 } & 5990 & 6300 & 6000 & 6890 & 6315 \\ \text { RS 4 } & 4565 & 5340 & 5100 & 5975 & 5915 \\ \text { Mean } & 4960 & 5895 & 5670 & 6435 & 6070 \\ \text { Mean selection intensity } & 6 & 78 & 28\end{array}$

(5) Differences for significance

\begin{tabular}{lcccc}
\hline \multicolumn{1}{c}{ Entries } & S.E. & K.S.D. $(0 \cdot 05)$ & \multicolumn{2}{c}{ S.E. $\times$} \\
2 treatments & $26 \cdot 06$ & 722 & 966 & 80 \\
Means of pairs & 18.43 & 511 & 664 & 40 \\
Means of 4's & 13.03 & 361 & 452 & 20 \\
Means of 8's & $9 \cdot 21$ & 255 & 304 & 10 \\
C. of V. & $9.7 \%$ & & &
\end{tabular}

(4) $\mathrm{S}_{1}$ testing

$\begin{array}{lrrrrr}\text { Popula- } & & & & & \\ \quad \text { ation } & -1 & \text { Base } & +1 & +2 & +3 \\ \text { PRS 1 } & 5265 & 5495 & \text { Yield } & 6720 & 7315 \\ \text { PRS 4 } & 5805 & 6160 & \text { trials } & 6605 & 6785 \\ \text { RS 2 } & 5735 & 6105 & & 5915 & 6860 \\ \text { RS 3 } & 4400 & 4600 & & 5910 & 6965 \\ \text { Mean } & 5300 & 5590 & - & 6290 & 6980 \\ & & & & 2 & 80\end{array}$

(6) Control yields

$\begin{array}{ll}\text { Serena 1 } & 6495 \\ \text { Serena 2 } & 6410 \\ \text { Serena 3 } & 6495 \\ \text { Serena mean } & 6465 \\ \text { Dobbs 1 } & 6265 \\ \text { Dobbs 2 } & 6100 \\ \text { Dobbs mean } & 6180\end{array}$

reason. In the evaluation trial, plant population density was only one-half of that used during the selection phase. In both the base populations and in the +1 populations, mean individual plant yields of steriles were significantly greater than those of fertile plants ( 44.0 to 36.8 and 50.9 to $40.4 \mathrm{~g}$ respectively) during the selection phase. This suggested a relative deficiency of lowyielding sterile plants, and is discussed later.

(ii) Height. Increasing height could not be controlled at the plant populations used. As far as possible, exceptionally tall plants were cut out before flowering. In the +1 generation, double the size of population was grown, and yield selection was confined to those plants below the mean 
height, the remainder being rejected. In the +2 generation, an arbitrary height was set, judged to be near the mean, and the same procedure followed. No attempt was made to control height in the $\mathrm{S}_{1}$ selection series.

(iii) Quality grain. In order to keep up the number of white grains in the quality grain bulks (PRS 2 and 4, RS 2 and 4), some of the heaviest yielding plants of this grain type were exchanged for some of the lower yielding selections in each grid square. The attempt was made to retain up to 50 per cent. of the corneous type in the final selected head numbers. This resulted in the top 5 per cent. selected for yield coming from the best 10 per cent. of high yielding plants in each square, while the next 5 per cent. might include some plants drawn from the top 20 per cent. of best yielders.

(iv) Wild-type characters. Plants with deciduous sessile spikelets ("shedders") occurred occasionally in the high-yield selections, as did some with very tight glumes or very small grains. These were replaced by the next highest yielders from the same grid square.
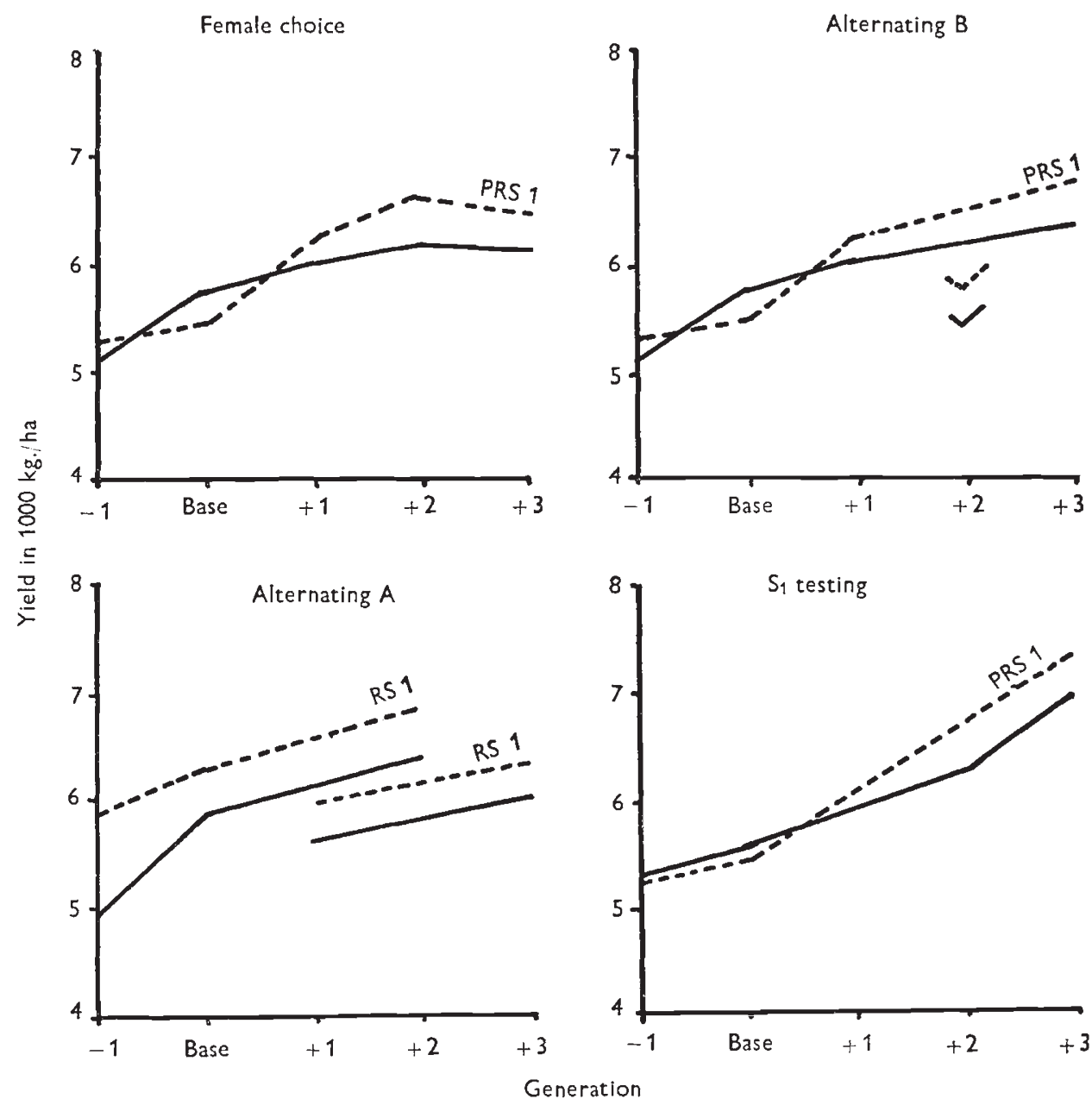

FrG. 1.-Yields of dried heads plotted against generation number. Solid line $=$ mean of all populations under selection: broken line $=$ most responsive populations. 
Generation

$-1$

Base

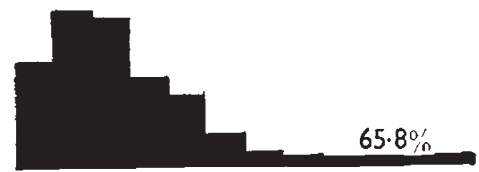

$+1$

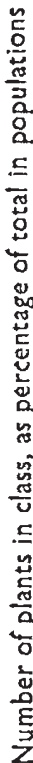

\section{Alternating $\mathbf{B}$}
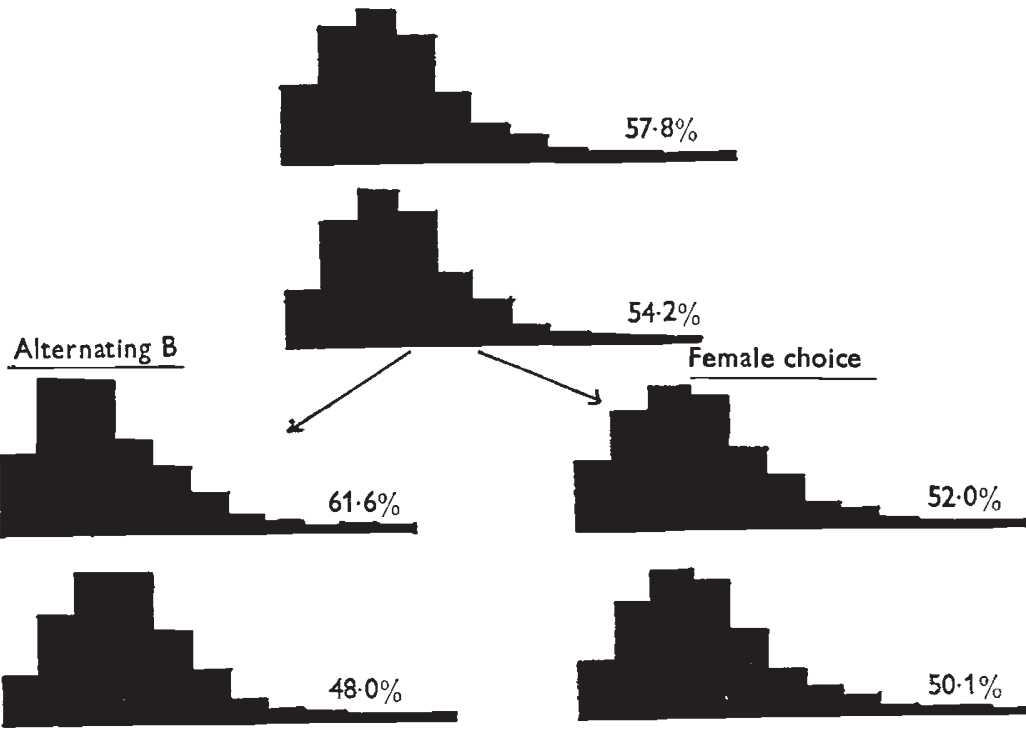

$+3$

Alternating $\mathrm{A}$

Base
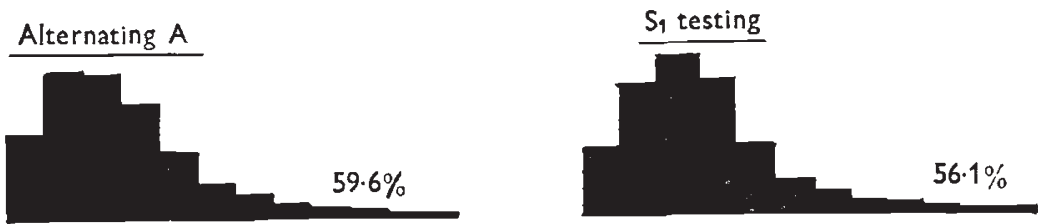

$+1$
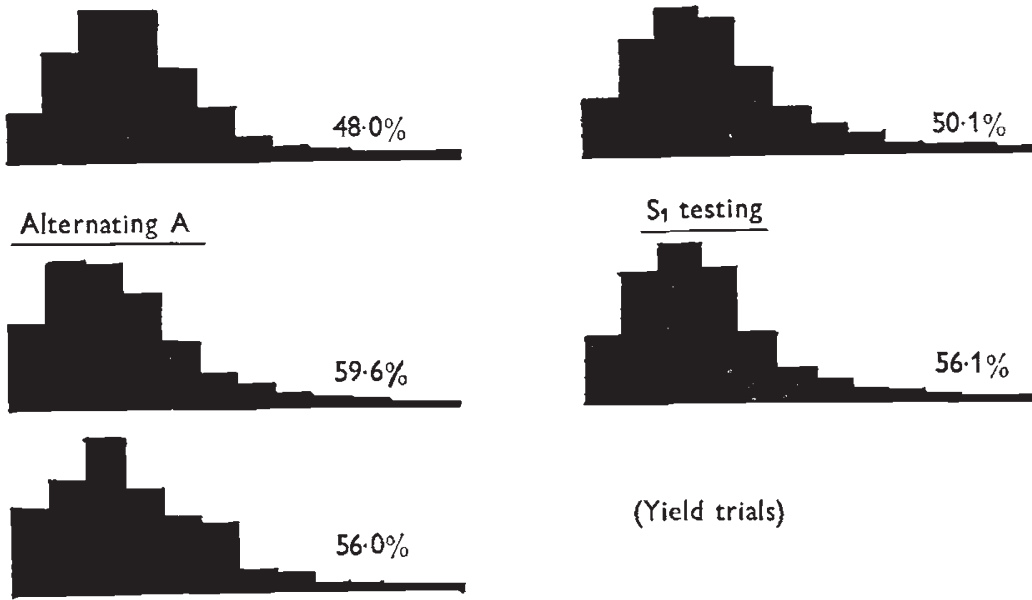

(Yield trials)

$+2$
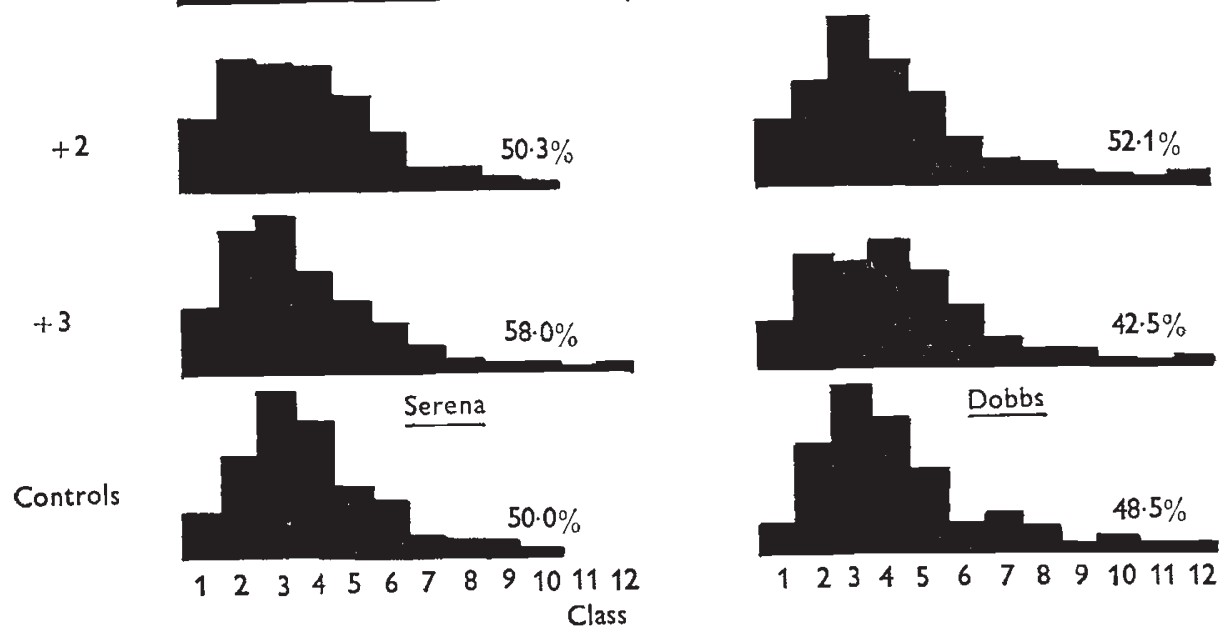

(Class interval $20 \mathrm{~g} ., \quad$ class $1=0-19 \mathrm{~g}$.)

Frg. 2.-Frequency distributions of yield from the sample plots, based on three replications and all populations under selection. Numerals show the percentage of population contained in the first three classes. 


\section{RESUlts}

\section{(a) rield}

The progress made by selecting for increased yield is shown in table 4 and fig. 1. Yields are expressed in kg./ha of dried, unthreshed heads, since selections were taken on such head weights. The mean selection intensities refer to the percentage of plants retained from the preceding generation to give the seed of the generation shown.

The graphs in fig. 1 show mean values for all the populations involved (solid line) and the behaviour of the population with the highest final yield (dotted line). For the alternating systems, the points representing the selfed generation values have not been joined to those of the random mating generations. Changes in the frequency distributions of individual plant yield for the population means under the different selection systems are shown in fig. 2.

(b) Length of maturity

Changes in maturity length were small, and are shown in table 5.

TABLE 5

Time in days from germination to 50 per cent. flowering (means of all appropriate populations)

(1) Female choice

$\begin{array}{ccccc}-1 & \text { Base } & +1 & +2 & +3 \\ 58.9 & 58.4 & 58.4 & 58.9 & 58.4\end{array}$

(4) Alternating A

$\begin{array}{lllll}-1 & \text { Base } & +1 & +2 & +3 \\ 58.4 & 57 \cdot 8 & 62 \cdot 2 & 60.0 & 60.8\end{array}$

(2) Alternating $\mathbf{B}$

$\begin{array}{cc}+2 & +3 \\ 60.0 & 59 \cdot 6\end{array}$

(3) Controls

(c) Height

Mean height changes are shown in table 6.

TABLE 6 Mean heights of appropriate populations, in centimetres

(1) Female choice

$\begin{array}{lllll}\overbrace{-1} & \text { Base } & +1 & +2 & +3 \\ 216 & 233 & 249 & 249 & 254\end{array}$

(4) Alternating A

$\begin{array}{lllll}-1 & \text { Base } & +1 & +2 & +3 \\ 218 & 232 & 250 & 254 & 237\end{array}$

(2) Alternating B

+2
+3
235 $\quad 252$

(3) Controls

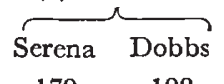

$179 \quad 198$

In view of the differences in numbers of steriles between the selection phase and the evaluation trial, the height and yield relationships of the populations were examined in greater detail. An analysis of sample plots was available from the +1 generation of female choice mass selection, which had been grown at 200,000 plants/ha in a season in which stress periods had 


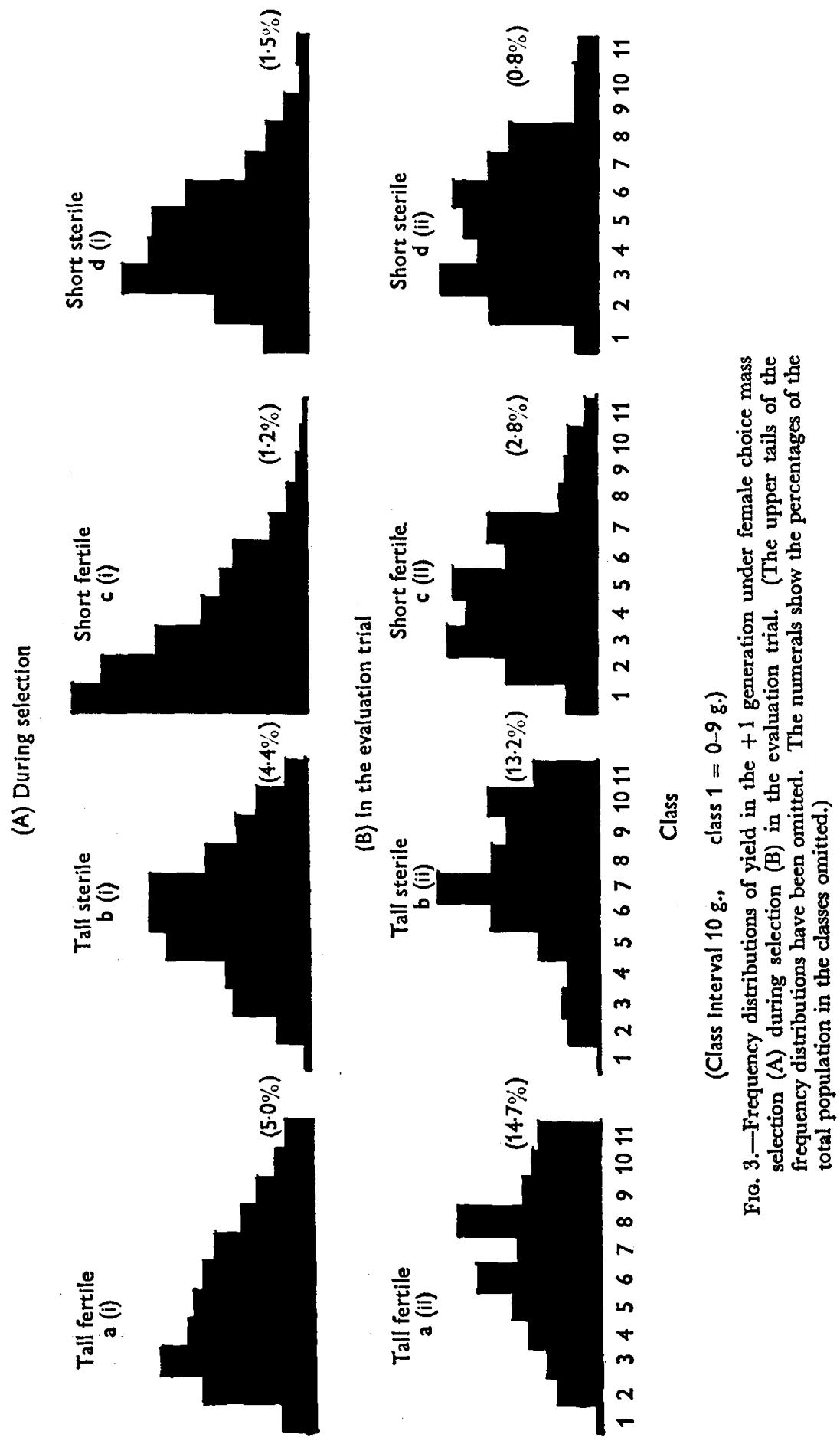


occurred during growth. Plant heights had been split into two groups, below and above the mean height (" tall " and "short "), and the separation was good (4145 talls to 4146 shorts), while individual plant yields were available from all 8291 plants. The identical generation in the trial had been grown at 100,000 plants/ha in a season of uniformly good growing conditions. Numbers were smaller, and the height grouping less even ( 564 tall to 498 short) but these numbers were still sufficient to give a reasonable idea of the frequency distributions of individual plant yields for the four groups, tall and short, fertile and sterile. These are shown in fig. 3: in this figure, the upper "tails" of the distributions have been omitted, the proportion of the curve omitted being indicated as a percentage figure in brackets. The changes in percentages of sterile plants in the tall and short groups under selection are shown in fig. 4.

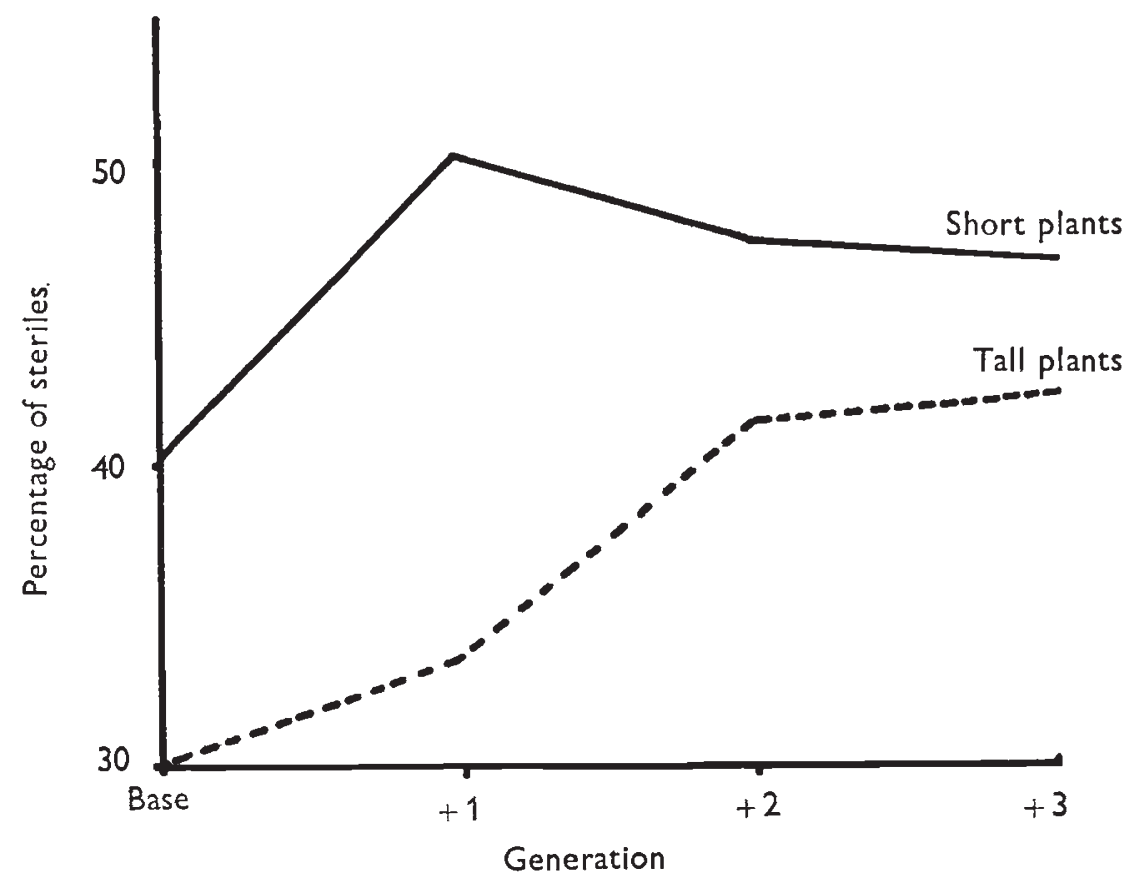

FIG. 4.-Percentage of steriles plotted against generation for the populations under female choice mass selection. (Data from the evaluation trial.)

There were no features of special interest in the height distribution changes of the populations under selection, and in view of the over-riding influence of competition, details are not presented. The proportion of steriles in the populations under selection was shown in table 3.

\section{(d) White grains}

The percentages of white grains are shown in table 7. These populations in which white grains were given preference (W. grain) being shown separately from those in which no preference for grain colour was shown (O. grain). 
TABLE 7

Mean percentage of white grains under selection

(1) Female choice

$\begin{array}{lrrrrr} & -1 & \text { Base } & +1 & +2 & +3 \\ \text { W. grain } & 23.9 & 18.8 & 15.8 & 17.5 & 14.7 \\ \text { O. grain } & 5.1 & 7.8 & 5.9 & 5.3 & 5.2\end{array}$

(3) Alternating A

$\begin{array}{lrrrrr} & -1 & \text { Base } & +1 & +2 & +3 \\ \text { W. grain } & 24.3 & 16.8 & 12.9 & 10 \cdot 1 & 22 \cdot 7 \\ \text { O. grain } & 3.3 & 5.2 & 9.8 & 3.3 & 8.8\end{array}$

(2) Alternating B

$\begin{array}{rr}+2 & +3 \\ 24 \cdot 8 & 17 \cdot 8 \\ 12 \cdot 0 & 3 \cdot 2\end{array}$

(4) $S_{1}$ testing

$\begin{array}{rlrr}-1 & \text { Base } & +2 & +3 \\ 23.4 & 20 \cdot 9 & 17.9 & 13 \cdot 8 \\ 6.9 & 10 \cdot 4 & 4.8 & 6 \cdot 2\end{array}$

\section{(e) Grain size}

The cleaned grain was separated with No. 10 and No. 8 sieves (mean hole diameters in sixty-fourths of an inch). Differences were slight in the proportions passing the No. 8 sieve, varying from 2 to 8 per cent., but were substantial between treatments for grains retained by the No. 10 sieve (large grains). These results are shown in table 8 .

\section{Table 8}

Percentages of large grains in the populations under selection, retained by a No. 10 sieve (10/64 inch hole diameter)

(1) Female choice

$\begin{array}{lllll}\overbrace{-1} & \text { Base } & +1 & +2 & +3 \\ 29.7 & 34.7 & 35.0 & 36.1 & 31.8\end{array}$

(2) Alternating B

$\overbrace{+2} \overbrace{+3}$

(5) $S_{1}$ testing

$\begin{array}{rrrrr}\overbrace{-1} & \text { Base } & +1 & +2 & +3 \\ 28.8 & 36 \cdot 4 & 27 \cdot 8 & 32 \cdot 3 & 28 \cdot 2\end{array}$

\begin{tabular}{|c|c|c|}
\hline-1 & Base & +2 \\
\hline $30 \cdot 6$ & $32 \cdot 9$ & $31 \cdot 9$ \\
\hline
\end{tabular}

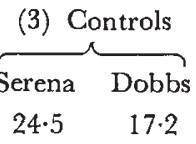

L.S.D. $(\mathbf{P}=0 \cdot 05)$

(1) and (2) $5 \cdot 1$

(4) and (5) $7 \cdot 2$

\section{(f) Wild-type characters}

"Shedders" were unexpectedly few in number. A total of only 28 such plants was found in the 10,000 sampled from the populations. Their distribution followed no recognisable pattern, and the only consistent feature was the presence of one of these plants in each of the +3 generations of the populations under $\mathrm{S}_{1}$ testing.

\section{Discussion}

The use of eight populations to which different selection systems were applied simultaneously provided enough replication to detect significant trends at an early stage.

\section{(a) rield}

The sorghum populations responded to selection for higher yield (as measured by dry, unthreshed head weight per plant in very evenly spaced plantings), just as might have been expected (fig. 1 and table 4). Populations responded to varying degrees, PRS 1 and RS 3 proving very responsive to all selection systems used. (RS 3 had a low-yielding base population, and some 
simple character such as leaf disease resistance probable accounts for its good responses). PRS 3, on the other hand, was relatively unresponsive to selection. Different degrees of response to selection shown by different replications are well known to workers on Drosophila, as are generation-togeneration fluctuations in response (e.g. Glayton et al., 1957; Frankham et al., 1968a). Selection pressures were generally low, apart from the selections chosen by $S_{1}$ trial, and those taken from the base populations to form the +1 generation of the "alternating $A$ " system. This was due to the desire to retain the breeding potential of the populations, and was mistaken. Evidently two sets of populations are required. One set would be kept to retain the development potential of the composites by using a selection intensity of about 50 per cent. (Dempster, 1955; Robertson, 1960), or as near that level as possible while still retaining all cultivated plant characters. The other set would be initiated from this maintenance population, and would be subjected to intense selection.

The Dobbs control variety had unusually small grains, indicating that, with its longer maturity (table 5) it had dried prematurely. Its yield would have been somewhat higher if the grain had developed fully.

The responses were relatively good, having regard to the selection pressures used. In the female choice system, mean gains were 8 per cent. over two generations, while two populations gained 20 and 30 per cent. over the base levels. All these differences are significant at $P=0 \cdot 05$. No gain was shown in the third generation, which can be ascribed at least in part to the attempt to concentrate on short plants, coupled with the low selection intensity of 50 per cent. in generation +2 from which the +3 generation was grown.

The alternating systems both show sharp depression on inbreeding, followed by a greater rise in the following recombination generation. The mean population yield increases over base in the +2 generation of alternating $\mathrm{A}$ (9 per cent.) and the +3 generation of alternating $\mathrm{B}$ ( 11 per cent.) were both significant. Further, in alternating $A$, with two inbreeding generations, the mean +3 value of $6070 \mathrm{~kg}$./ ha was just significantly greater that the +1 value of $5670 \mathrm{~kg}$. $/$ ha (a 7 per cent. increase) and the suggestion is that a further rise of some 10 per cent. would occur in the next recombination generation.

The yield increases from $\mathrm{S}_{1}$ testing were unexpectedly large. This cannot be claimed as being due to the breeding method, as the selection pressure in the testing generation was so much higher than any other used ( 2 per cent.). It is noticeable that the +2 generation did not produce an inbreeding depression in three of the populations, though there were indications of such an effect in RS 2. The mean result was a 12 per cent. increase, yet the seed for this generation was from sibbed or selfed heads. The recombination generation showed a further boost, so that there was a mean yield increase of 25 per cent. over the base population equivalent to $+1390 \mathrm{~kg} . / \mathrm{ha}$. Further, the mean yield of the +3 generation was significantly greater than the control means, while PRS 1 at $7315 \mathrm{~kg}$. $/ \mathrm{ha}$ was $820 \mathrm{~kg}$./ ha above the best Serena entry, this difference being real. To one who has spent a number of years trying to beat Serena and Dobbs by conventional breeding methods this was a remarkable result, even when allowance is made for the fact that lines withdrawn from this population would show a yield depression on inbreeding. 
The last point of great interest in table 4 and fig. 1 is the size of the yield increase from the last generation of compositing $(-1)$ to the base population -averaging about 10 per cent. This was not foreseen, or seed of the other generations would have been retained for testing. Indeed, an initial decline in yield was expected, because although the fitness of a random-mating population cannot decline, the intercrossing of numerous selfed lines could lead to a reduction of gametic excess due to changes in the degree of recombination, with a corresponding reduction in mean fitness during the formation of the random-mating population (Turner, 1967a, $b$ ). In fact, in every population and in every breeding system tested, recombination following inbreeding resulted in a substantial yield boost. The last compositing generations seem to have been in this category, in spite of the fact that some selection was applied during compositing. Growing selfed heads resulted in inbreeding depression, excepting for the +2 generation of $\mathrm{S}_{1}$ testing. This exception is probably accounted for by the reduced intensity of inbreeding-one-half of the heads were sibbed-and by the high intensity of selection for yield. This manifestation of heterosis on recombining groups of inbred lines from the same breeding population also occurs in cotton, as shown by Walker (1963) for the BP 52 multiline NG 54 . The effect could be of value in obtaining increased yields, and may not be confined to sorghum and cotton among the mainly self-pollinated crops.

The distribution of yields under the various systems of selection are shown in fig. 2. The histograms are skewed towards the low end, and the reason for this will be apparent when competition effects are discussed below. The changes in yield distribution under selection involve some reduction in the skewness with increasing yield, and may be conveniently seen from the changes in the percentage of the entries occurring in yield classes 1-3, as indicated by the figures on the diagram.

\section{(b) Length of maturity}

Yield increases were not associated with any large changes in maturity length, and the highest yielding group, generation +3 under $S_{1}$ testing, was of similar maturity length to Serena (table 5). However, it is rather clear that selection for high yield in the $S_{1}$ lines had favoured the later maturing material, as shown by a mean maturity length of 64.5 days to 50 per cent. flowering in generation +2 .

\section{(c) Height and male-sterility}

The superficial impression given by table 6 is that selection for increased yield has resulted in the selection of the taller phenotypes. However, competition greatly influenced this conclusion. From fig. 3 it can be seen that for tall, fertile plants in the selection regime, the peak of the histogram is in height class 3 (fig. $3 a$ (i)) while in the trial, there is a peak in class 6 and another in class 8 , with a fairly symmetrical form (fig. $3 a$ (ii)). Under the stress conditions of the selection plots, even the tall plants were being pressed by competition, and a disproportionate number gave low yields. A more normal distribution was obtained under the easier growing conditions of the trial. The contrast in the short fertile plants is much more striking. Under the stress conditions of selection, the maximum of the short fertile distribution is in yield class 1 , with steadily declining numbers in successive 
classes (fig. $3 c$ (i)). The corresponding histogram from the trial (fig. $3 c$ (ii)) shows a more normal distribution, but even so, there is a far greater proportion of the entries in the first three yield classes than in the same classes of the tall plant histogram (fig. $3 a$ (ii)). Evidently, under the conditions of selection, short plants were suffering severely, so that selection for yield inevitably favoured the talls. This is consistent with the competition studies of Rao and Rachie (1964). No conclusions may be drawn regarding the relative potential yielding abilities of the plants in the short and tall halves of the yield distribution curve.

The reason for using dense stands was in order to select plants which would be competitive, and able to utilise high fertility levels effectively. This merely served to force up the height. Continual selection at high density was mistaken (cf. Turner, 1967b) and the best procedure would have been to select at low plant densities for a part of the time, permitting a much wider range of phenotypes to survive, recombine, and contribute to the population. High-density selection would be done in other generations, for the reasons already given. In other words, doing exactly what Ford (1964) has shown occurs in nature with some seasons easy and some seasons hard. Evidently selection at very high densities should be avoided until the general height of the population has been selected to a reasonably uniform level. O. J. Webster (personal communication) found no difficulty in reducing height in a random-mating sorghum population by selection.

A further feature of the competition effects demonstrated in fig. 3 is the relative vulnerability of male-sterile plants. Their distributions do not depart from the normal nearly so markedly as those for fertile plants (fig. $3 b$ and $d$ ), but the numbers of steriles under the stress conditions of selection (talls, 25 per cent., shorts 28 per cent.) were substantially below those in the easier trial conditions (talls, 36 per cent., shorts 50 per cent.). Taken in conjunction with the higher mean yields of sterile plants under stress conditions ( $51 \mathrm{~g}$. to $40 \mathrm{~g}$.), this must surely mean that a higher proportion of low yielding steriles was eliminated through competition. The difference between $c$ (i) and $d$ (i) in fig. 3 therefore lies in the elimination of a lot of the plants from yield classes 1 and 2 in $d$ (i). The suggestion of persistent linkage between $m s_{3}$ and shorter plants is supported by the graph from the female choice selection system in the trial (fig. 4). No linkage values may be calculated because of the competition effects, but the indications are clear. Such persistence of linkage is only to be expected, through closeness of linkage, and also because the genetic architecture includes genes which reduce recombination (e.g. Catcheside, 1968), but does again underline the importance of not squeezing too hard by using high planting densities all the time during selection.

\section{(d) Quality characters}

It proved possible to maintain white grains in the populations at a useful level without difficulty. In the absence of deliberate selection pressure they remained in the populations at levels of around 5 per cent. (table 7). Threshing percentage was not subjected to selection, and there were no apparent trends in this character, Serena having the highest value and Dobbs the lowest. The percentage of clean grain obtained from the winnowed grain with a "Clipper" seed cleaner showed no significant differences, any apparent trend being towards a higher proportion of clean grain. Thus, the 
levels of these two important cultivated characters were well maintained. None of the differences in grain size was important (table 8) : all populations showed higher apparent values than Serena, and in many cases these mean differences were significant. The high yields of the $S_{1}$ populations in the +3 generation were not accompanied by any increase in grain size. There is a slight suggestion that inbreeding reduced grain size in the alternating series. The premature drying of Dobbs grain was noted earlier.

\section{(e) Abnormal segregates}

Plants with wild-type characters appeared in the populations, and so did abnormal segregates, as had occurred in barley (Harlan, 1956). They were not unexpected, as complementary gene action for characters such as shedding ( $S h_{2}$ and $S h_{3}$, Karper and Quinby, 1947) was bound to occur. At times their frequency seemed rather high in the selection phase, and gave rise to some concern. This aspect of the analysis of the evaluation trial was not done as thoroughly as could be desired, because facilities became overloaded. However, even if types showing non-cultivated characters were present at several times the frequency estimated, their number would still represent only 1-2 per cent. of the total, and the problem need not get out of hand. The use of much lower plant populations would doubtless permit more abnormal segregates to survive, but many of them could be identified early and prevented from flowering.

\section{(f) Changed procedures}

The populations have been combined into two separate composites, restorer and non-restorer. The main modifications now made have been the separation of the maintenance and development composites, and the use of wide spacing for part of the selection period. The development composites have been split up into relatively small, isolated subpopulations. Selection is being applied to these in more than one way, with replication, and probably with some difference in objectives between subpopulations. The case for this is good (Wright, 1931; Baker and Curnow, 1969), and the system may simplify selection for quality. At all stages, the populations will be used as sources of individual plant selections, for handing by conventional breeding methods. Suitable lines from the populations will be combined into synthetics, and the composition and value of synthetics will be studied.

Hybrids will always be important in sorghum, and the basic separation of composites as potential male and female parents will be continued. It was too early to test for changes in the expression of yield heterosis between these two main population divisions in the present study. The results of Burton et al. (1970) with maize indicate how promising this approach may be, with heterosis for yield worth $+10.2 \mathrm{q} . /$ ha at the $\mathrm{C} 4$ generation compared to $+3.9 \mathrm{q}$. $/$ ha for the same cross at the $\mathrm{C} 2$ generation. A series of subpopulations within each of the two main populations is likely to enhance the chances of finding high values for heterosis between populations and their derivatives.

A biometrical approach to this work would obviously be valuable. For those who are not biometricians, progress may be monitored by checks on the values of the population's haploid additive genetic variance $V_{H}$ (Turner, 1969), so that the composite can be discarded when no longer showing profit- 
able responses. The most effective methods of $S_{1}$ testing will obviously be adopted, but much development will be possible without the necessity for delving more deeply into biometrical studies.

\section{(g) General considerations}

Response to selection is a basic property of populations exhibiting variability in the character favoured. It represents a part of the brilliant exploitation of the DNA molecule by the creative activity of the Word of God. Various forms of selection in Drosophila populations involving random or assortive mating have led to large, and long continued, responses. A recent series of such trials were recorded by Frankham et al. $(1968 a, b)$, and by Jones et al. (1968), who cited numerous references to other work. Recurrent selection in maize populations is achieving solid success (Sprague, 1967; Eberhart et al., 1967). Recurrent selection in populations of crossbreeding pasture species is standard procedure in many grass breeding programmes (e.g. Graomann, 1952; Breese, 1960) although the comments of Fyfe (1970) would indicate that the composites are not always very broadly based. Simmonds (1966) obtained responses from the application of recurrent mass selection to broadly based populations of Andigena potato seedlings. It is difficult to imagine a situation in which a random-mating population of a crop plant would not respond in the desired direction to recurrent selection pressures correctly applied and of sufficient intensity. However, this method has not as yet been used generally in the mainly selfpollinating crops, although several crop plants show a sufficient measure of natural outcrossing, and male-sterility is available for use in other cases.

Barley is the example of success using broadly based populations. In the U.S.A., Composite CC II outyielded the "Atlas" control after some 20 generations: CC XIV, containing a male-sterile, surpassed " Atlas " after 10 generations. The barley composites have served as source material for numerous varieties (Harlan, 1956; Suneson, 1956). Suneson (1956) considered that the growing of composites in mass, under competitive natural selection, constituted an evolutionary plant breeding method. However, crop plants are not the products of evolution through natural selection. Their cultivated characters have been developed and maintained by strong human selection acting against natural selection, often in a disruptive manner (Doggett and Majisu, 1968). In barley, "black seed" was eliminated under this evolutionary breeding system (Suneson, 1956), but it would be interesting to know what deliberate selection pressures were applied to retain cultivated characters. Simmonds (1968) has emphasised the value of developing this kind of population breeding approach in cereals.

Cotton composites have also been successful: Albar was a composite established from 39 plants screened out of a large Nigerian "Allen" population, in which introgression with Gossypium punctatum had occurred (Hutchinson, 1959). Excellent varieties have been developed from " Albar" in several African countries, two types in Uganda yielding 20-30 per cent. above the highly bred varieties which they replaced (Arnold et al., 1968). The " modal bulk" system was a narrowly based population method to which stabilising recurrent selection was applied (Manning, 1955). Using modal bulks in BP 52, U.P.A., and Albar cottons, it proved impossible to 
prevent a steady upward creep in yield of 1 to 2 per cent. per year (Walker, 1965; Riggs, 1967). It would be interesting to see the effects of applying directional recurrent selection for yield to such populations, while attempting continued stabilising selection for the quality characters.

The apparent failure of the broad-based cotton composite, the panmixis, (Harland, 1955; Hutchinson, 1959) has been a stumbling-block to the acceptance of population methods by some plant breeders. Hutchinson (1959) described a panmixis based on 19 diverse cotton types, maintained under " a modest degree of selection". The last phrase supplies the key to the problem: unlike the Albar composite, which was selected to a definite objective, the panmixis was run on a stir-the-pot-and-hope philosophy (Hutchinson, personal communication). Intense, deliberate human selection for the important cultivated characters is essential if crop plants are to be maintained and improved: if great variability is released by forming a panmixis, then " a modest degree of selection" for cultivated characters of importance may be difficult to apply in all the directions required, and may not suffice. Natural selection can be very powerful (Ford, 1964) and could take over, so that wild-type characters would oust the cultivated. The alternatives are either to apply more general and intense selection, or to form the panmixis by stages. The latter is likely to retain more of the useful variability. A series of separate composites, each covering a fairly narrow band of quality, would seem to be feasible, judging from the variation in the present Uganda multiline seed issues (Walker, 1963). As these were developed, suitable components from them would be formed later into fresh composites. The fact that the initial very widely based panmixis was unsuccessful in no way detracts from the correctness and value of the concept. The problems of how to utilise the wide range of variability in cotton through the use of controlled panmixia are under active investigation, while recurrent selection systems are already in use (Arnold et al., 1970).

\section{(h) Selection for yield}

Hutchinson (1940) accepted Balls' (1919) stress on the importance of selection for the components of yield, because yield itself could not be measured with sufficient accuracy, and therefore could not be subjected to effective selection. The development of this approach in cotton led to the application of a selection index technique (Manning, 1956; Hutchinson, 1959). The weakness of any such component selection system is that the model used is always too simple. Modern techniques of yield measurement made it possible to revert to selection for yield per se, thus treating the plant as an integrated whole (Hutchinson, 1940). The yield of the plant is the outcome of all the complexities of interaction between genotype and the environment in which it was grown. High "fitness" involves maximising the use of available limiting resources (Turner, 1967b) and direct selection for yield under growing conditions which are as good as limiting resources can make them must surely be the most effective way of achieving optimum fitness. Modern techniques of $S_{1}$ testing make this possible. Evidently testing is needed over a range of the environments in which the crop is to be grown. There is sufficient complexity in selecting for multiple agronomic and quality characters, without adding a serjes of yield components which can never account fully for all the factors which produce the final yield. 


\section{(i) Conclusions}

Breeders of the mainly self-pollinated crops have not yet taken advantage of the information obtained over the past 30 years from population genetics and maize breeding. The responses of random-mating populations to recurrent selection result from fundamental properties of living organisms. Such responses must therefore occur provided (i) that the necessary variability is present, and (ii) that appropriate selection pressures are applied. These latter must be of sufficient intensity to overcome any disparate natural selection pressures. Much remains to be learnt on methods. Ample variability is present in the crop plants, but the full range may not be usable initially in one composite, because of difficulties in applying sufficient selection pressures over a wide enough range of characters, while still retaining the development potential. The use of a number of sub-composites should solve this problem. Modern systems of $\mathrm{S}_{1}$ testing have removed many of the difficulties of applying selection pressures for complex characters such as yield. We have insufficient information on how best to improve two or more complex characters in the same population. Much help on this could be obtained from studies in populations of organisms such as Drosophila involving simultaneous selection for at least two characters such as body weight and chaeta number over many generations.

The system outlined by Eberhart et al. (1967) and Doggett and Eberhart (1968) should be most profitable. Two main composites expressing good heterosis when crossed would be improved in isolation by recurrent selection, probably being divided into subpopulations. Hybrids between derivatives of the two composites would permit the temporary formation of fitter genotypes. Where suitable sterility systems exist, such hybrids would be the normal commercial product in developed countries until the populations themselves had reached maximum yield levels. This would take a long period of time. The flexibility of the system makes it suitable for developing as well as developed countries. The composites can be sources of material for the creation of conventional varieties, multiline mixtures, synthetics, varietal hybrids or conventional hybrids.

\section{Summary}

1. Eight separate sorghum populations were made up rom a total of 158 varieties, using the genetic male-sterile $m s_{3}$, and composited for at least three generations before applying selection. The basic split was into restorer and non-restorer groups when tested on the cytoplasmic male-sterile CK 60A.

2. Four selection systems were used:

(a) Female choice mass selection on all eight populations for three cycles.

(b) Alternating selfed plant and female choice mass selection on all eight populations for one cycle.

(c) Alternating mass selection on four populations for one and a half cycles.

(d) $\mathrm{S}_{1}$ testing for one cycle on four populations.

3. Selection for yield was effective under all systems, and most effective under $S_{1}$ testing in which the Serena control was outyielded (6980-6465 kg./ha -of dried heads). 
4. Selection intensities were low, except for the $\mathrm{S}_{1}$ testing system.

5. Inbreeding depression in yield occurred on selfing, followed by a yield increase on recombination.

6. Plant competition resulted both in the favouring of tall plants and the partial elimination of low yielding $m s_{3}$ individuals.

7. All cultivated characters were maintained without difficulty, and the proportion of wild-type characters remained very low.

8. Current improvements include divisions of the two basic groups into small subpopulations to be selected separately, and the use of low plant populations for a part of the selection period.

9. Since response to selection is a basic property of random-mating populations, recurrent selection methods must be effective, though more needs to be learnt about methods of application to crop plants.

10. The development potential of this method applied to populations of the mainly self-pollinating crops seems very great. Where suitable sterility systems are available, the normal commercial product will be hybrids between derivatives of the two basic composite groups. These latter would be progressively improved by the continuous application of recurrent selection.

Acknowledgments.-I am indebted to Dr G. D. H. Bell, Professor Sir Joseph Hutchinson, Professor K. Mather, Dr O. Starnes and Professor J. M. Thoday for reading and commenting on the manuscript: also to Dr S. A. Eberhart, Dr B. N. Majisu and Dr G. F. Sprague for helpful discussion. The paper was made possible by the careful work of the supporting staff at Serere, especially Mr R. Okello, Mr P. Ajau, Mr S. Kasule and Mr B. Okwi. I am grateful to the Rockefeller Foundation for continued financial support in the sorghum work.

\section{REFERENGES}

ARNOLD, M. H., COSTELLOE, B. E., AND CHURCH, J. M. F. 1968. BPA and SATU, Uganda's two new cotton varieties. Cott. Gr. Rev. 45, 162.

ARNold, M. H., INNes, N. L., AND GRIDlAy, H. E. 1970. Cotton Breeding. Prog. Rep. Exp. Sta. Cot. Res. Corp. London, Ann. Rep. 1969-70, p. 12.

BAKER, L. H., AND CURNOW, R. N. 1969. Choice of population size and use of variation between replicate populations in plant breeding selection programmes. Crop. Sci. 9, 555.

BALLS, W. L. 1919. The Cotton Plant in Egypt. MacMillan, London.

BELL, G. D. H. 1968. Plant breeding for crop improvement in Britain. Proc. Roy. Soc. B. 171, 145.

BREESE, E. L. 1960. The genetic assessment of breeding material. Proc. 8th. Int. Grassland Cong., 45.49.

BURton, J. W., hallaueR, A. R., EBERHART, S. A., AND PENNY, L. H. 1970. Recurrent selection for yield in the maize variety (BSK) Agron. Abstracts, 62nd meeting, p. 6.

CATCHESIDE, D. E. A. 1968. Regulation of the AM-1 locus in Neurospora: evidence of independent control of allelic recombination and gene expression. Genetics, 59, 443.

CLAYTON, G. A., MORRIS, J. A., AND ALAN ROBERTSON. 1957. An experimental check on quantitative genetic theory. I. Short-term responses to selection. 7. Genet., 55, 131.

DEMPSTER, E. R. 1955. Genetic models in relation to animal breeding problems. Biometrics, 11,535 .

Drxon, G. E. 1960. A review of Wheat Breeding in Kenya. Euphytica, 9, 209.

DOGGETT, H. 1968. Mass selection systems for sorghum. Crop. Sci., 8, 391.

DOGGETT, H. 1970. Sorghum. Longman's, London.

DOGGETT, H., AND EBERHART, s. A. 1968. Recurrent selection in sorghum. Crop Sci., 8, 119. DOGGETT, H., AND MAJISU, B. N. 1968. Disruptive selection in Crop Development. Heredity, 23,1 .

EBERHART, S. A., HARRISON, M. N., AND OGADA, F. 1967. A comprehensive breeding system. Der Zuchter, 37, 169. 
FORD, E. B. 1964. Ecological Genetics. Methuen, London.

FRANKHAM, R., JONES, L. P., AND BARKER, J. S. F. 1968a. The effects of population size and selection intensity in selection for a quantitative character in Drosophila I. Genet. Res. Camb., 12, 237.

FRANKHAM, R., JONES, L. P., AND BARKER, J. S. F. 1968 $b$. The effects of population size and selection intensity in selection for a quantitative character in Drosophila III. Genet. Res. Camb., 12, 267.

FYFe, J. L. 1970. Grass breeding. 49th Ann. Rep. Scottish Plant Breeding Sta., 1969-70, 21-27.

GRAOMANN, H. O. 1952. The polycross method of breeding in relation to synthetic varieties and recurrent selection of new clones. Proc. 6th Int. Grassland Cong., 314-319.

HARLAN, J. R. 1956. Distribution and utilization of natural variability in cultivated plants. Brookhaven Symp. Biol., 9, 191.

HARLAND, s. C. 1955. Plant Breedings: present position and future perspective. Third Bateson Lecture, John Innes Institute (quoted by Simmonds, N. W., Biol. Rev., 1962, 37, 442).

HEARN, A. B. 1969. The growth and performance of cotton in a desert environment III. Crop performance. 7. Agric. Sci. Camb., 73, 87.

Hutchinson, J. B. 1940. The application of genetics to plant breeding 1. The genetic interpretation of plant breeding problems. J. Genetics, 40, 271.

Hutchinson, J. B. 1959. The Application of Genetics to Cotton Improvement. Cambridge University Press.

JONES, L. P., FRANKHAM, R., AND BARKER, J. S. F. 1968. The effects of population size and selection intensity in selection for a quantitative character in Drosophila II. Genet. Res. Camb., 12, 249.

KARPER, R. E., AND QUINBY, J. R. 1947. The inheritance of callus formation and seed shedding in sorghum. $\mathcal{F}$. Hered., 38, 211.

manning, H. L. 1955. Response to selection for yield in cotton. Cold Spr. Harb. Symp. Quant. Biol., $20,103$.

MANNING, H. L. 1956. Yield improvement from a selection index technique with cotton. Heredity, 10, 303.

NORDQUist, P. 1965. Sorghum Annual Report, U.S.D.A., A.R.S. (Mimeographed). Washington D.C.

QUinby, J. R., AND schertz, K. F. 1970. Sorghum Genetics, Breeding, and Hybrid Seed Production. Sorghum Production and Utilization, ed. Wall and Ross, 73. A.V.I., Westport, Connecticut.

RAO, D. v. N., AND RACHIE, K. O. 1964. Survival of Genotypes in a Mixture of fourteen sorghum varieties. Ind. F. Genet. and Plant Breed., 24, 22.

RIGGs, T. J. 1967. Response to modal selection in Upland Cotton in Northern and Eastern Uganda. Cott. Gr. Rev., 44, 176.

Robertson, A. 1960. A theory of limits in artificial selection. Proc. Roy. Soc. B., 153, 234. srmmonds, N. w. 1966. Studies of tetraploid potatoes III. F. Linn. Soc. (Bot.), 59, 279-288. simmonds, N. w. 1968. The Cereal breeding situation. 47th Ann. Rep. Scottish Plant Breeding Sta., 1967-68. 16-34.

sprague, G. w. 1967. Plant Breeding. Ann. Rev. Genetics, 1, 269.

SUNESON, C. A. 1956. An evolutionary plant breeding method. Argon. J., 48, 188.

TURNER, J. R. G. 1967a. On supergenes I. The evolution of supergenes. Amer. Nat., 101, 195.

TURner, J. R. G. 1967b. Mean fitness and equilibria in multilocus polymorphisms. Proc. Roy. Soc. B, $169,31$.

TURNER, J. R. G. 1969. The basic theorems of Natural Selection. Heredity, 24, 75.

walker, J. T. 1963. Multiline concept and Intra-varietal heterosis. Emp. Cott. Gr. Rev., $40,190$.

WAlkeR, J. T. 1965. Modal selection in Upland cotton. Heredity, 19, 599.

whitehouse, R. N. H. 1969. Barley breeding at Cambridge. Rep. Pl. Breed. Inst. Cambridge, $1968,6$.

WRIGHT, s. 1931. Evolution in Mendelian populations. Genetics, 16, 97. 